\begin{tabular}{|l|l|l||}
\hline \multicolumn{2}{|c|}{ PublisherInfo } \\
\hline \hline PublisherName & $:$ & BioMed Central \\
\hline \hline PublisherLocation & $:$ & London \\
\hline \hline PublisherImprintName & $:$ & BioMed Central \\
\hline \hline
\end{tabular}

\title{
Treatment of autoimmune disease with allogeneic BMT
}

\begin{tabular}{|l|l|l||}
\hline \multicolumn{2}{|c|}{ ArticleInfo } \\
\hline \hline ArticleID & $:$ & 10 \\
\hline \hline ArticleDOI & $:$ & $10.1186 /$ ar-2000-66793 \\
\hline \hline ArticleCitationID & $:$ & 66793 \\
\hline \hline ArticleSequenceNumber & $:$ & 6 \\
\hline \hline ArticleCategory & $:$ & Paper Report \\
\hline ArticleFirstPage & $:$ & 1 \\
\hline \hline ArticleLastPage & $:$ & 3 \\
\hline \hline & & RegistrationDate : 2000-3-20 \\
\hline ArticleHistory & $:$ & OnlineDate \\
\hline \hline ArticleCopyright & $:$ & Current Science Ltd2000-3-20 \\
\hline \hline ArticleGrants & $:$ & \\
\hline \hline ArticleContext & $:$ & 130752211 \\
\hline \hline
\end{tabular}




\section{Keywords}

Allogeneic, autoimmune, autologous, bone marrow transplantation, MRL/lpr

\section{Context}

Although allogeneic BMT can be used to treat a variety of autoimmune diseases in both autoimmunity-prone mice and humans, autologous BMT is currently carried out in humans in order to prevent graft-versus-host rejection and incomplete T-cell recovery. One drawback is that autoimmunity frequently recurs rapidly or persists following autologous BMT. Co-injection of donor stromal cells with T-cell-depleted allogeneic BMT increases tolerance of the transplant; however, the bone grafting required for stromal cell recruitment is inappropriate for use in humans. A new strategy that demonstrates donor cell tolerance, prevents recurrence of autoimmune disease, and is suitable for use in patients is required. To test a new method of allogeneic BMT in the treatment of autoimmune disease.

\section{Significant findings}

PV injected BMCs gave rise to a higher survival rate than intravenously injected cells. Seventy percent of mice treated with fractionated irradiation followed by PV injection of BMCs (5.5 Gy x $2+$ PV) survived for one year. However an additional intravenous injection 5 days after the PV injection (5.5 Gy x $2+$ PV + IV) increased the survival rate of the MRL/lpr mice to $100 \%$ at one year. Higher doses of irradiation or PV injections of T-cell-depleted BMCs in conjunction with irradiation resulted in higher mortality rates. Lower doses of irradiation were insufficient in depleting residual MRL/lpr hematopoietic stem cells (HSCs), resulting in a recurrence of autoimmune disease. When injected through the PV, almost 100\% of donor hepatic mononuclear cells, spleen cells and BMCs were found in the recipient mice. In contrast there was only a transient rise in the percentage of donor cells present in the intravenously injected mice. Compared to untreated MRL/lpr mice at 20 weeks, 5.5 Gy x $2+\mathrm{PV}+$ IV treated MRL/lpr mice showed significantly lower levels of autoantibodies at 48 weeks. Anti-SRBC levels in treated mice were higher than those in untreated animals, and treated mice displayed a $\mathrm{T}$ cell tolerance to both host and donor type MHC determinants while demonstrating a normal mixed leukocyte response to third party cells. Together these results indicate restoration of normal function of antigenpresenting cells, T cells and B cells in the 5.5 Gy x $2+$ PV + IV treated MRL/lpr mice. Pathological examination of the glomeruli from MRL/lpr mice showed IgG deposits and a proliferation of mesangial cells, whereas treated MRL/lpr mice appeared normal. 


\section{Comments}

This study uses MRL/lpr mice to test a new strategy for allogeneic bone marrow transplantation that, the authors claim, is suitable for use in the treatment of human autoimmune disease. The treatment of symptomatic MRL/lpr mice with fractionated irradiation and injections of allogeneic bone marrow cells, results in a remarkable survival rate of $100 \%$. Although this paper is sometimes ambiguous and confusingly written, this novel approach does appear to overcome three of the major problems observed with current bone marrow transplantation (BMT) strategies: (1) graft-host rejection; (2) recurrence of autoimmune disease; (3) the need for extensive immunosuppressive therapy. It now remains to be demonstrated whether the successful treatment of autoimmune disease in this animal model can be replicated in humans.

\section{Methods}

Bone marrow cells (BMCs) were collected from the femurs and tibias of B6 mice. T cells were depleted using a monoclonal antibody against Thy1.2. The onset of autoimmune diseases in MRL/lpr mice was monitored by checking for proteinuria and lymphadenopathy. Autoimmune mice were irradiated in fractionated doses. In addition $3 \times 10^{7}$ whole BMCs were injected either via the portal vein (PV) or intravenously. Hepatic mononuclear cells were isolated from the liver following perfusion of the mice with heparinized phosphate buffered saline (PBS) and then collagenase. Immunological functions of the mice were assessed by determining antibody production against sheep red blood cells (SRBCs) and by mixed leukocyte reaction. Cell surface phenotypes were determined by flourescence activated cell sorter (FACS) analysis. Rheumatoid factor and anti-ssDNA antibodies were measured by ELISA.

\section{References}

1. Kushida T, Inaba M, Takeuchi K, Sugiura K, Ogawa R, Ikehara S: Treatment of intractable autoimmune diseases in MRL/lpr mice using a new strategy for allogeneic bone marrow transplantation. Blood. 2000, 95: 1862-1868.

This PDF file was created after publication. 